\title{
Intensity-Modulated Proton Therapy
}

National Cancer Institute

\section{Source}

National Cancer Institute. Intensity-Modulated Proton Therapy. NCI Thesaurus. Code C159611.

A type of proton beam radiation therapy in which complex spatial control of the proton beam is achieved through modulation of the dose, deflection, and penetration. 